\title{
AVALIAÇÃO RADIOGRÁFICA DA APLICAÇÃO DO POLÍMERO DE MAMONA EM FALHAS ÓSSEAS INDUZIDAS EM EQUINOS
}

\author{
Peterson Triches Dornbusch ${ }^{1}$, Ivo Guilherme Ribeiro de Araujo ${ }^{2}$, Ubirajara Yobe \\ Tasquetti ${ }^{3}$, Claudia Turra Pimpão ${ }^{3}$, Antonia Maria Binder Prado ${ }^{3}$, \\ Carlos Alberto Hussni ${ }^{4}$
}

\author{
Universidade Federal do Paraná - petriches@gmail.com \\ Universidade Federal do Maranhão \\ Pontificia Universidade Catolica do Paraná \\ Faculdade de Medicina Veterinária e Zootecnia - Unesp, Campus de Botucatu/SP.
}

RESUMO: Avaliou-se por radiografias o comportamento do polímero de mamona aplicado no preenchimento de falhas ósseas induzidas em equinos. Para tal utilizaram-se cinco equinos, submetidos à tranquilização e anestesia local, seguindo-se a indução cirúrgica de falhas ósseas nas porções distais laterais dos rádios direito e esquerdo de cada animal, promovendo-se perfurações de três centímetros de profundidade, utilizando-se broca de oito milímetros de diâmetro. O membro direito serviu de controle, sem preenchimento da falha induzida. A falha realizada no membro esquerdo foi preenchida com o polímero comercial derivado da mamona. Foram avaliados o edema localizado e os aspectos radiográficos como: o estabelecimento de escores para o preenchimento ósseo, para a esclerose e ainda foi feita a análise morfométrica da área de esclerose, aos 15, 45, 90 e 180 dias de evolução. Observou-se maior edema e inchaço local nos membros cujas lesões foram preenchidas com polímero de mamona. Comparativamente, os exames radiográficos demonstraram melhor preenchimento ósseo nas falhas dos membros controle. Conclui-se que o preenchimento com polímero de mamona em falhas ósseas induzidas no rádio de equinos retardou a cicatrização óssea, sob o ponto de vista radiográfico.

Palavras-chave: cimento ósseo; equinos; polímeros; Ricinus Communis

\section{RADIOGRAFHIC EVALUATION OF CASTOR OIL BEAN POLYMERIC APLICATION IN EQUINE INDUCED BONE FLAWS}

ABSTRACT: It was evaluated the radiographs alteration of the castor oil bean polymer applied for the filing of induced bone fault in horses. Five animals were evaluated, subjected to a local anesthesia and sedation, proceeding to a surgical induction of a hole in the radio bone, in both members with three centimeters depth perforations. It was used a drill of eight millimeters of diameter. The right member served as a control, without filling induced holes. The holes in left radio were filled with the commercial polymer derived from the castor oil bean. We evaluated the localized swelling and radiological aspects as: the establishment of scores for bone filling, sclerosis and a morphometric analysis of the sclerosis area, in 15, 45, 90 and 180 days of lesion evolution. There was more swelling in local members whose injuries were filled with polymer from castor oil bean. By comparison, the radiographic examination showed better bone filling in the gaps of members control. We concluded that the completion of castor oil bean polymer in bone holes induced in radio of horses, delayed the bone healing, in the radiographic evaluation.

Key words: bone cement; equine; polymers, Ricinus communis 


\section{INTRODUÇÃO}

Os equinos, por serem utilizados em atividades esportivas, estão sujeitos a traumas que podem acarretar fraturas. O tratamento destas fraturas tem evoluído nos últimos anos, especialmente devido às novas tecnologias aplicadas nos materiais cirúrgicos. São poucos os trabalhos sobre a utilização de cimentos ósseos em equinos, sendo que estes se restringem a relatos de casos (Hickman et al., 1984). Por outro lado, atualmente são realizadas 200 mil cirurgias anuais, em seres humanos, envolvendo enxertos ósseos autógenos, alógenos e substitutos sintéticos heterólogos. Evidências preliminares indicam que a eficácia dos enxertos sintéticos deverá no futuro ultrapassar os demais substitutos ósseos graças à evolução tecnológica aplicada nestes materiais (Heest e Swiontkontkowski, 1999). Os substitutos ósseos podem ser biológicos ou sintéticos, sendo que os biológicos podem ser classificados como: autólogos, homólogos e heterólogos. Enxertos homólogos são geralmente conservados por congelamento ou glicerina. Os heterólogos, derivados de ossos bovinos, são disponíveis na forma liofilizada. Ossos autólogos são considerados o "padrão ouro" dos enxertos ósseos, entretanto a sua disponibilidade é limitada (Conz et al, 2005).

A utilização de osso autólogo oferece uma desvantagem do ponto de vista cirúrgico que é a necessidade de uma segunda intervenção para a coleta de material suficiente, especialmente na crista ilíaca ou do osso esterno, o que eleva o tempo de cirurgia e aumenta os riscos de complicações transoperatórias. Como alternativa para preencher falhas ósseas, surgiram os cimentos ósseos, substâncias sintéticas que facilitam a reparação óssea, permitindo rápida osteogênese, osteoindução e osteocondução, (Franco, 2000), podendo mostrar resultados tão bons quanto os obtidos com o uso dos enxertos autólogos (Heest e Swiontkowski, 1999). Entretanto estudos mostram que alguns cimentos ósseos provocam morte celular, o que leva a intolerância desta prótese (Ciapetti et al., 2000). Dentre os muitos polímeros e plásticos desenvolvidos até o momento como substitutos ósseos, o polimetilmetacrilato, o ácido polilático e o ácido poliglicólico são os mais utilizados em cirurgia oral, ortopédica, neurológica e plástica reconstrutiva. Podemos citar ainda os materiais inorgânicos como a hidroxiapatita e o fosfato tricálcico (Zambuzzi, 2005). As próteses e cimentos a base de fosfato de cálcio, são utilizada intensamente, pois estudos in vivo mostram uma boa osteointegração (Piolletti, et al, 2000). Yuan et al, 2000, sugerem ainda, que estas próteses são osteocondutivas e osteoindutivas.

No Brasil foi desenvolvido a partir de 1984, pelo Grupo de Química Analítica e Tecnologia de Polímeros da Universidade de São Paulo, campus de São Carlos, sob a coordenação do Prof. Dr. Gilberto Chiérice, um polímero a base de moléculas vegetais extraídas da mamona, cuja estrutura molecular se assemelha a existente nos organismos vivos (Leonel, et al, 2003). Este polímero associado ao fosfato de cálcio mostrou-se eficaz na reparação óssea em coelhos (Ohara et al., 1996 e Mazer et al., 1997). A poliuretana de mamona pode ser utilizada pura ou em associação com o carbonato de cálcio, sendo a função do carbonato fornecer íons cálcio, o que facilita a troca iônica na interface osso-resina, com incremento do mecanismo de deposição de cálcio na matriz colágena nas várias 
fases do processo de reparação óssea (Maria et al., 2003).

$\mathrm{O}$ presente estudo visa avaliar $\mathrm{o}$ comportamento radiográfico do cimento ósseo a base de polímero de mamona no preenchimento de falhas ósseas induzidas, para verificar a necessidade do preenchimento de perfurações ósseas pequenas, como as deixadas após a retirada de implantes metálicos, nos equinos.

\section{MATERIAL E MÉTODOS}

Foram utilizados cinco equinos hígidos, previamente vermifugados, alimentados com feno ad libtum e mantidos em piquetes. Os animais foram tranquilizados com romifidina, na dose de $80 \mathrm{ug} / \mathrm{kg}$ e butorfanol, na dose de $0,05 \mathrm{mg} / \mathrm{kg}$, feita a preparação de rotina. Em seguida foi realizada tricotomia na face lateral da região distal do rádio e anti-sepsia com álcool iodado $5 \%$, em ambos os membros torácicos. Procedeu-se a anestesia local infiltrativa do terço distal do rádio, face lateral, com lidocaína a $2 \%$ sem vasoconstritor. Realizou-se a incisão de pele na face lateral do rádio, terço distal, estendendo-se de proximal a distal com aproximadamente três centímetros de comprimento. $O$ tecido subcutâneo foi divulsionado e em seguida foi rebatido o periósteo e acessada a córtex óssea lateral. A falha óssea foi produzida por perfuração, com broca de oito milímetros de diâmetro e três centímetros de profundidade, até atingir a medula óssea. A falha produzida no rádio esquerdo foi preenchida com cimento ósseo a base de polímero de mamona. A perfuração da cortical do rádio direito serviu de controle, não sendo preenchida. $O$ tecido subcutâneo foi suturado com fio de poliglactina 2-0 e a pele com nylon 2-0. No pós-operatório os animais receberam penicilina procaína, na dose de $20.000 \mathrm{Ul} / \mathrm{kg}$ e flunixim meglumine, na dose de 1 $\mathrm{mg} / \mathrm{kg}$, durante três dias.

Os animais foram examinados diariamente quanto à presença de claudicação. Analisou-se, ainda, a presença de edema e aumento de volume no local da cirurgia, em ambos os membros.

Exames radiográficos foram realizados no terço distal de ambos os rádios de cada animal, aos 15, 45, 90 e aos 180 dias, com projeções crâniocaudal e lateromedial, no qual se buscou avaliar o tempo para o preenchimento da falha óssea, a área de esclerose endosteal e a reatividade periosteal. Para graduar visualmente as lesões foi criado um escore para o preenchimento ósseo das perfurações, ilustrado na Tabela 1. A interpretação radiográfica foi realizada na forma de estudo cego, realizado por radiologista, sendo que as imagens radiográficas foram identificadas somente por códigos, não permitindo reconhecer os animais e os momentos.

Tabela 1 - Escores do grau de preenchimento ósseo visto nas radiografias em projeção lateromedial e craniocaudal.

\begin{tabular}{cl}
\hline Escore & Apresentação \\
\hline 0 & $\begin{array}{l}\text { Sem preenchimento ósseo. } \\
\text { Fundo da falha óssea preenchido } \\
(25-30 \%) .\end{array}$ \\
2 & $\begin{array}{l}\text { Metade da falha óssea } \\
\text { preenchida (50\%). } \\
\text { Mais que } 50 \% \text { de preenchimento } \\
\text { na da falha óssea. }\end{array}$ \\
\hline
\end{tabular}

Tabela 2 - Escore visual para interpretação do grau de esclerose óssea peri-lesional, visto nas radiografias em projeção latero-medial e crâniocaudal.

Grau Interpretação

0 Esclerose não visível.

1 Visível em contorno parcial.

2 Visível em contorno total, porém delgada.

3 Visível em contorno total e espessa.

A análise da área de esclerose foi realizada de duas formas: por meio de 
um escore visual, em estudo cego, mostrado na tabela 2 e ainda, por um estudo morfométrico, no qual todas as radiografias foram digitalizadas e analisadas com o software Epona Tech Metron 3.01.

Para a análise estatística dos dados numéricos obtidos foi utilizada a análise de variância a um critério (ANOVA ONE - WAY), com nível de significância de 5\%. Para os dados do escore visual foi utilizado o teste de Student, com nível de significância de $5 \%$. Todos os cálculos foram realizados utilizando o Software estatístico GraphPad Prism version 3.00 for Windows, San Diego - Califórnia, EUA.

\section{RESULTADOS}

Todos os animais apresentaram claudicação discreta de ambos os membros que persistiu na primeira semana após a cirurgia. As feridas cirúrgicas cicatrizaram sem intercorrências, com a retirada dos pontos da pele no décimo dia. A região operada apresentou aumento de volume localizado que regrediu lentamente nas duas semanas de pós-operatório, no lado direito (controle) e durante quatro semanas no lado esquerdo (enxerto).

$A$ análise radiográfica do preenchimento ósseo, pelo escore visual, para a incidência crânio-caudal, mostrou diferenças significativas somente no último momento de avaliação, aos 180 dias $(p<0,01)$, sendo que o membro controle apresentou melhores resultados. Por outro lado, quando observado o preenchimento ósseo, na incidência lateromedial, aos 15 dias houve maior preenchimento nos membros esquerdos (Polímero), porém os membros do lado direito (Controle) mostraram melhores resultados aos 90 dias $(p<0,05)$ e 180 dias $(p<0,01)$, (Figura 1).

O escore visual para interpretação do grau de esclerose óssea peri- lesional, visto nas radiografias em projeção lateromedial apresentou resultados significativamente maiores, aos 180 dias, no lado esquerdo $(p<0,05)$. A análise morfométrica da área de esclerose radiográfica não demonstrou diferenças estatísticas entre os dois grupos. Estes valores estão apresentados na Figura 2.

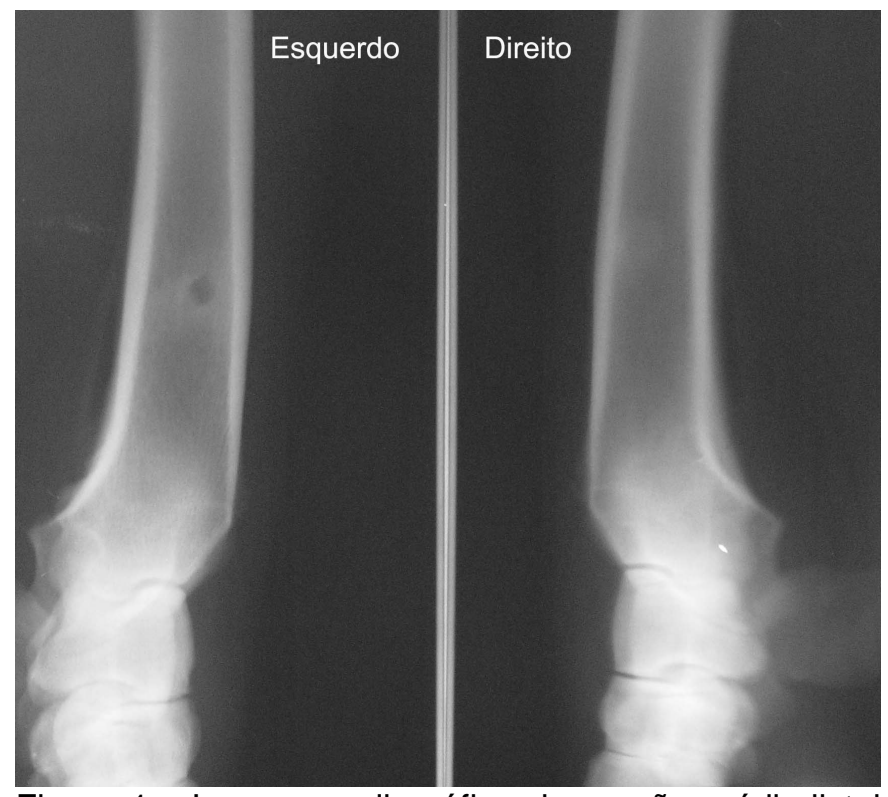

Figura 1 - Imagem radiográfica da porção médiodistal do rádio de equino, obtida aos seis meses de avaliação da lesão óssea. O lado esquerdo foi preenchido com cimento ósseo a base de polímero de mamona, enquanto o lado direito serviu de controle.

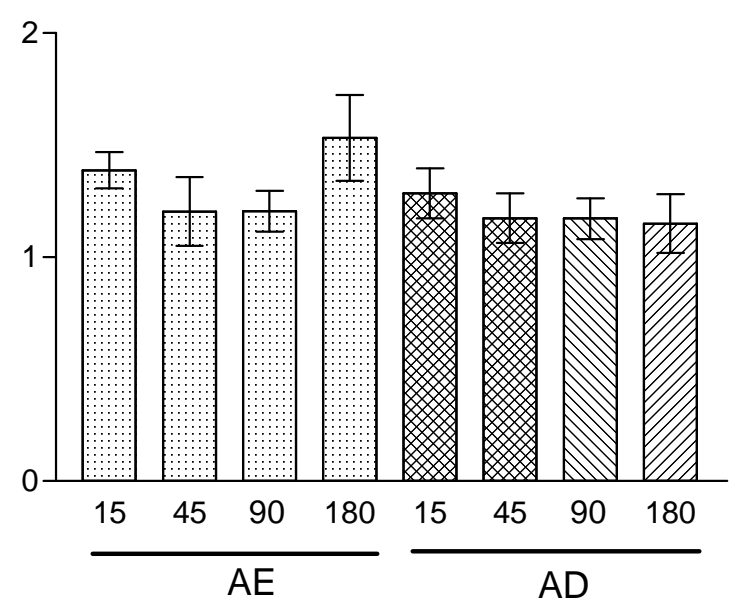

Figura 2 - Área de esclerose, em centímetros quadrados, obtidos nos momentos 15, 45, 90 e 180 dias após as perfurações do osso rádio preenchido com polímero de mamona (esquerdo) e sem preenchimento (direito), mensuradas nas radiografias com incidência lateromedial $(p<0,05)$. 


\section{DISCUSSÃO}

A utilização de implantes na fixação interna de fraturas, em diversas espécies animais, tem sido exaustivamente estudada. Assim como as suas complicações associadas: infecção, perda do implante, não-união óssea e a fadiga do implante. Casos de recorrência de fraturas em uma região já consolidada têm sido amplamente relatados (Bostman, 1990; Yang et al., 2005), devendo-se principalmente aos efeitos adversos de placas rígidas na estrutura cortical e a fragilidade causada pelos orifícios deixados pela remoção dos parafusos (Rosson et al,1991). O preenchimento dos orifícios remanescentes com cimentos ósseos é alvo de controvérsias. Muitos estudos têm sido realizados em cães, ratos, coelhos e aves, no intuito de comprovar a eficiência do polímero derivado da mamona, na substituição óssea, com resultados favoráveis na maioria dos casos (Pereira Jr, 2005).

O local padronizado para indução do defeito ósseo utilizado neste trabalho mostrou-se de fácil execução por permitir a indução das lesões ósseas com o animal em apoio quadrupedal, procedimento este adaptado de Miclau et al. (1996), que criaram orifícios de 4,5 $\mathrm{cm}$ de diâmetro na diáfise femoral de cães adultos preenchendo os defeitos com enxerto esponjoso autólogo, em que os orifícios apresentaram menor formação de calo ósseo e ausência de tecido cartilaginoso em todos os períodos de observação, com rápida incorporação do enxerto. Além disso, Supõe-se que a melhora na incorporação do enxerto estaria associada à menor ruptura do suprimento sanguíneo endosteal e periosteal, não criando instabilidade óssea. A coleta de materiais com remoção de fragmentos ósseos para estudo histopatológico poderia tornar necessária a eutanásia dos animais, o que tem sua aplicação limitada por questões éticas, e portanto não praticada neste experimento.

A avaliação dos substitutos ósseos deve considerar se são osteocondutores e promovem aposição de tecido ósseo em sua superfície, funcionando como um molde que facilita a neoformação óssea. Este molde deve fornecer um substrato no qual células osteoblásticas possam crescer, diferenciar-se e depositar matriz óssea extracelular, além de serem biocompatíveis (Lu et al., 2000). Outra característica desejável é a osteointegração, definida como uma ancoragem direta de um implante pela formação de tecido ósseo ao redor deste, sem o crescimento de tecido fibroso na interface osso-implante (Merck, 2005).

Do ponto de vista clínico a maior reação local, caracterizada pelo edema mais prolongado, nos membros onde foi implantado o polímero de mamona, demonstra certa reatividade inflamatória. Entretanto a análise radiográfica morfométrica e do grau de esclerose no rádio não sugere maior reação óssea, portanto a reação pode ter se dado apenas no tecido subcutâneo, ocasionado por eventuais resíduos do polímero de mamona, pois este foi aplicado na fase pastosa da reação de polimerização. $\mathrm{Em}$ favor destes fatos colaboram os achados de Maria et al. (2003) que demonstraram que a poliuretana de mamona não desencadeia processos infecciosos ou de rejeição no tecido ósseo do hospedeiro e é biocompatível, permanecendo biotolerante ao longo do tempo, podendo, entretanto, não ocorrer osteointegração. Del Carlo et al. (2003) constataram que o polímero de mamona quando acrescido de cálcio permite a ocorrência de osteogênese e osteocondução, principalmente quando adicionadas células tronco, e que permite a migração de capilares, de 
tecidos perivasculares e de células osteoprogenitoras.

Ziliotto et al. (2003), trabalhando com aloenxerto preenchido com 0 polímero de mamona, em cães, não obtiveram osteointegração. Contrariando estes resultados Pereira Junior (2005), obteve osteointegração deste polímero quando estudou o seu comportamento na diáfise do rádio de coelhos. Isto demonstra a controvérsia entre autores, que se deve a diversos fatores como a espécie animal estudada, o modelo experimental, a localização e o tamanho das lesões, além da carga biomecânica aplicada e do tempo de acompanhamento do estudo.

Dentre os diversos fatores que influenciam diretamente no comportamento dos polímeros in vivo, Cons et al. (2005) verificaram que os parâmetros de cristalinidade, área superficial e composição podem ser usadas para estimar a biodegradabilidade da hidroxiapatita e como critério de controle de qualidade desses materiais. Outro ponto a ser considerado é a porosidade de um cimento ósseo, sendo que dentre as propriedades do polímero de mamona, deve ser citada a presença de poros irregulares em meio a sua estrutura, com o objetivo de propiciar a neoformação tecidual e vascular dentro dos mesmos (Leonel et al., 2003). O tamanho destes poros é de fundamental importância, pois a quantidade de osso neoformado é diretamente proporcional ao diâmetro dos poros (Blitterswijk et al, 1986). Entretanto o resultado de estudos sobre o preenchimento destes poros é controverso, pois o tempo de reabsorção do polímero de mamona varia conforme a espécie utilizada, sendo que alguns estudos tem demonstrado uma taxa de osteointegração considerada lenta, principalmente se comparado ao osso autólogo (Pereira Jr., 2005). No estudo realizado por Popak et al. (2003), o polímero de mamona não apresentou osteointegração, quando implantado na tíbia de cães.

Silva et al. (1997), concluiu que análises quantitativa de radiocapacidades nas imagens radiográficas convencionais e digitalizadas mostram similar desempenho, servindo ainda de critério de padronização e reprodutibilidade para avaliação do processo de reparo ósseo e relações de interface na pesquisa de materiais aloplásticos substitutos ósseos biocompatíveis. De forma semelhante, a avaliação radiográfica ora estudada foi satisfatória na observação da reparação de uma pequena falha óssea induzida no rádio de equinos, sendo possível identificar o retardo na cicatrização promovido pelo polímero de mamona. Em concordância com Fernandes et al. (2007), que concluíram em estudo experimental em cães, histologicamente não há rejeição, caracterizando biocompatibilidade, porém não ocorrendo reparação óssea nas lesões preenchidas com o polímero. Estes achados diferem totalmente daqueles observados por Leonel et al. (2004), que observaram que o polímero de mamona auxiliou no processo regenerativo do defeito ósseo criado experimentalmente, atuando como um agente osteocondutor em ratos.

Devido aos efeitos contraditórios entre as pesquisas realizadas em diferentes espécies, mais estudos serão necessários para verificar os aspectos envolvidos na osteointegração, em equinos.

\section{CONCLUSÃO}

O preenchimento de falhas ósseas de oito milímetros de diâmetro com polímero de mamona, no osso rádio de equinos, demonstrou retardar a cicatrização óssea, sob o ponto de vista radiográfico. 


\section{REFERÊNCIAS}

BLITTERSWIJK, V.; GROTE, J.; KUIJPERS, W. et al. Macropore tissue ingrowth: a quantitative and qualitative study on hydroxyapatite ceramic. Biomaterials, v.7, p.137-43. 1986.

BOSTMAN, O.M. Refracture after removal of a condilar plate from the distal third of the femur. Journal of Bone and Joint Surgery. v.72 , n.7, p.1013-1018, 1990.

CIAPETTI, G.; GRANCHI, D.; CENNI, E. et al. Cytotoxic effect of bone cements in HL-60 cells: distinction between apoptosis and necrosis. Journal Biomedical Material Research, v 52, n.2, p.338-45, 2000.

CONZ, M.B.; GRANJEIRO, J.M.; SOARES, G.A. Physicochemical characterization of six commercial hydroxyapatites for medical dental applications as bone graft. Journal Applicated Oral Science. v.13, n. 2, p.136-4, 2005.

DEL CARLO, R.J.; KAWATA, D.; VILORIA, M.I.V. et al. Polímero derivado de mamona acrescido de cálcio, associado ou nào a medula óssea autógena na reparação de falhas ósseas. Ciência Rural, v 33, n 6, p.1081-88, 2003.

FERNANDES, S.E.; BORGES, A.P.B.; VILORIA, M.I.V. et al. Avaliação histológica do polímero derivado do óleo de mamona (Ricinus communis) aplicado na diáfise proximal da tíbia de cães. Revista Brasileira de Ciências Veterinárias, v.14, n.2, 63-66, 2007.

FRANCO, K.L.; BORGES, A.P.B.; VILÓRIA, M.I.V. et al. Hidroxiapatita sintética pura, hidroxiapatita sintética associada ao colágeno e hidroxiapatita sintética associada ao lipossoma como substitutos ósseos em defeitos provocados na tíbia de cães: aspectos da osteointegração à microscopia de luz transmitida. Arquivo Brasileiro Medicina Veterinária e Zootecnia, v.53, n.4, 1-7, 2001.

HEEST, V.A.; SWIONTKOWSKI, M. Topical issues in select specialties: Bone-graft substitutes. Lancet, v.353, n.1, p.28-29, 1999.

HICKMAN, J; KOLD, S.E; ELLIS, D.R. et al. Use of bone cement in two equine orthopaedic cases. Equine Veterinary Journal, v.16, p.54345, 1984.

LEONEL, E.C.F.; MANGILLI, P.D.; RAMALHO, L.T.O. et al. A importância da porosidade interna do polímero de mamona durante a neoformaçao óssea-estudo em ratos. Ciência Odontologica Brasileira. v. 6, n.3, p.19-25, 2003.

LEONEL, E.C.F; ANDRADE SOBRINHO, J.; RAMALHO, L.T.O. et al. A ação do polímero de mamona durante a neoformação óssea. Acta Cirurgica Brasileira, v.19, n.4, p.342-50, 2004.

MARIA, P.P.; PADILHA FILHO, J.G.; CASTRO, M.B. Macroscopic and histopathologic evaluations of the use of polyurethane resins derived from castor oil (Ricinus communis) applied in the tibia of the puppies. Acta Cirurgica Brasileira, v.18, n.4, p. 332-36, 2003, MAZER N, BARBIERÍ C.H., IGNÁCIO H. Uso das poliuretanas derivadas do óleo de mamona para preencher defeitos ósseos diafisários segmentares de rádio (Estudo experimental em coelhos). Revista Brasileira de Ortopedia , v.3, p.815-21, 1997.

MICLAU, T.; LINDSEY, R.W.; PROBE, R.; RAHN, B.A.; PERREN, S.M. Autogenous cancellous bone graft incorporation in a gap defect in the canine femur. Journal Orthopedic Trauma, v.10, n.2, p.108-113, 1996.

OHARA, G.H.; KOJIIMA, K.E.; ROSSI, J.C.; et al. Estudo da biocompatibilidade do Bio Ósteo implantado intra-ósseo e intra articular em coelhos. Acta Ortopedica Brasileira, v.3, p.6268, 1995.

PEREIRA JÚNIOR, O.C.M. Comparação entre polímeros de mamona (Ricinus communis) e auto-enxerto ósseo esponjoso no tratamento de defeito ósseo segmentar induzido no rádio de coelhos. 2005. Botucatu, $67 f$. Dissertação (Mestrado em Medicina Veterinária) - Faculdade de Medicina Veterinária e Zootecnia de Botucatu, Universidade Estadual Paulista.

PIOLLETTI, D.P.; TAKEI, H.; LIN, T. et al. The effects of calcium phosphate cement particles on osteoblast functions. Biomaterials, v. 21, n.11, p.1103-14, 2000.

POPAK, P.M.; PADILHA, J.G.; CASTRO, M.B. Análise macroscópica e histológica do emprego da poliuretana derivada do óleo de mamona (Ricinus communis) aplicada na tíbia de cães em fase de crescimento. Acta Cirúrgica Brasileira. v.18, n.4, p. 322-35, 2003

ROSSON, J.; EGAN, J.; SHEARER, J. et al. Bone weakness after the removal of plates and screws. The Journal of Bone and Joint Surgery. v.73 (B), n.2, p.283-86, 1991.

SILVA, M.J.A. Estudo radiográfico das imagens convencionais e digitalizadas do comportamento do tecido ósseo frente ao implante do polímero de mamona em coelhos. 1997. Bauru, 135f. Dissertação (Mestrado em Odontologia) - Curso de pósgraduação em Odontologia, Faculdade de Odontologia de Bauru, Universidade do Estado de São Paulo. 
YANG, K.H.; CHOI, Y.W.; WON, J.H. et al. Subcapital femoral neck fracture after removal of Gamma/Proximal Femoral nails: report of two cases. Injury Extra, v.36, p.245-48, 2005.

YUAN, H.; DE BRUIJN, J.D.; DE GROOT, K. et al. Tissue response of calcium phosphate cement: a study in dogs. Biomaterials, v.21, n.12, p.1283-90, 2000.

ZAMBUZZI, W.F.; OLIVEIRA, R.C.; ALANIS, D. et al. Tissue response to porous microgranula bovine anorganic boné implanted in rat sbcutaneous tissue. Journal Applicated Oral Science. v. 13, n.4, p.382-6, 2005.
ZILIOTTO, L; DALECK, C.R.; PADILHA FILHO, J.G.et al. Utilização de implante ósseo cortical alógeno conservado em glicerina para a preervação de membro torácico: Estudo experimental em cães. Acta Cirúrgica Brasileira, v.18, n.2, p.107-15, 2003. 